\title{
IoT Dalam Agrobisnis Studi Kasus : Tanaman Selada Dalam Green House
}

\author{
Nurliana Nasution $^{1}$ and Mhd Arief Hasan ${ }^{2}$ \\ Prodi Teknik Informatika, Fakultas Ilmu Komputer, Universitas Lancang Kuning ${ }^{1,2}$ \\ nurliananst@unilak.ac.id ${ }^{1}$, m.arif@unilak.ac.id ${ }^{2}$
}

\begin{tabular}{l}
\hline \hline Article Info \\
\hline History: \\
Dikirim 01 Juli 2019 \\
Direvisi 01 Agustus 2019 \\
Diterima 14 September 2019
\end{tabular}

Kata Kunci:

Agribisnis

IoT

Kontrol

Pertanian

\begin{abstract}
Abstrak
Internet of Things (IoT) merupakan sebuah paradigma dalam teknologi komunikasi yang terbaru saat ini yang membuat konsep zaman depan semakin lebih tampak, di mana semua benda di kehidupan sehari-hari akan dibekali dengan perangkat mikrokontroler, teknologi wireless digital, dan kumpulan protokol-protokol sesuai yang membuat mereka saling berkomunikasi antar satu dengan lainnya dan kemudian pengguna, menjadi bagian integral dari Internet.IoT bisa dimanfaatkan untuk banyak kegunanaan salah satunya untuk bidang pertanian dimana di penelitian ini akan di contohkan bagaimana pengontrolan tanaman bersifat otomatis melalui jaringan komunikasi ponsel. Ponsel digunakan sebagai alat bantu untuk mengontrol pemupukan, penyiraman, suhu dan kelembapan suatu ruangan.
\end{abstract}

(C) This work is licensed under a Creative Commons Attribution-ShareAlike 4.0 International License.

\author{
Koresponden: \\ Mhd Arief Hasan \\ Prodi Teknik Informatika, Fakultas Ilmu Komputer \\ Universitas Lancang Kuning \\ Pekanbaru, Riau \\ Email : m.arif@unilak.ac.id
}

\section{PENDAHULUAN}

Petani membutuhkan informasi pertanian dan pengetahuan yang relevan untuk membuat keputusan yang berpengetahuan dan untuk memenuhi kebutuhan informasi. Dalam domain pertanian melalui pengembangan sistem manajemen pengetahuan, pertanyaan petani dapat dijawab dengan bantuan multimedia yang mudah diakses.

Penerapan Teknologi Informasi dan Komunikasi (TIK) telah terbukti memperluas peluang untuk mempromosikan pertanian pada beberapa aspek dan domain di negara berkembang. Teknologi telah melewati rintangan dengan menggunakan teknologi nirkabel, jaringan, mobile dan lain-lain.

Untuk mengatasi penggunaan energi, listrik dan peralatan yang memakan biaya yang sangat membantu dalam pembangunan pertanian. Pengembangan ICT di berbagai domain telah mendorong minat substansial dalam meningkatkan investasi oleh sektor swasta terhadap pertumbuhan ICT dalam penelitian Pertanian $[1]$.

Internet of Things (IoT) merupakan sebuah paradigma dalam teknologi komunikasi yang terbaru saat ini yang membuat konsep zaman depan semakin lebih tampak, di mana semua benda di kehidupan sehari-hari akan dibekali dengan perangkat mikrokontroler, teknologi wireless digital, dan kumpulan protokol-protokol 
sesuai yang membuat mereka saling berkomunikasi antar satu dengan lainnya dan kemudian pengguna, menjadi bagian integral dari Internet [2].

Konsep IoT ada bertujuan agar internet lebih imersif dan meresap. Selain itu, dengan memungkinkan akses dan interaksi yang mudah dengan perangkat elektronis lainnya seperti, misalnya, alatan rumah tangga, CCTB, sensor pemantauan, aktuator, layar monitor, kendaraan, dan perangkat lainnya, IoT akan berdampak terhadap pengembangan aplikasi yang memanfaatkan jumlah dan variasi data yang besar yang dihasilkan oleh objek-objek guna memberikan layanan-layanan terhadap warga, perusahaan, dan pelayanan umum. Konsep ini memang menemukan aplikasi di banyak bidang yang berbeda, seperti sistem otomatisasi rumah, otomatisasi industri, pertolongan medid, layanan kesehatan, bantuan lansia, teknologi energi cerdas dan jaringan cerdas, otomotif, pengaturan lalu lintas, dan lainnya [3].

Teknologi IoT sangat tepat untuk di realisasikan pada bidang pertanian hal ini dikarenakan fungsi elektronisasi yang disediakan oleh IoT mampu menjawab semua tantangan yang di miliki oleh para petani. Sensor-sensor yang dimiliki IoT mampu dalam mendeteksi tingkat kesuburan tanah, pengendalian penyakit maupun hama. Dan juga teknologi wireless yang ada mampu untuk mendeteksi cuaca dan iklim. Kemudian produk teknologi IoT mampu dalam penjadwalan otomatisasi penyiraman, penyemprotan pestisida dan pemupukan. Oleh karenanya tim peneliti sangat tertarik untuk mengembangkan Teknologi IoT dalam agribisnis pertanian.

\section{INTERNET OF THING (IOT)}

Internet of things (IoT) adalah jaringan perangkat fisik, kendaraan, peralatan rumah tangga, dan barang-barang lainnya yang dibenamkan dengan elektronik, perangkat lunak, sensor, aktuator, dan konektivitas yang memungkinkan hal-hal ini untuk menghubungkan, mengumpulkan, dan bertukar data. IoT melibatkan perluasan konektivitas Internet di luar perangkat standar, seperti desktop, laptop, smartphone, dan tablet, ke berbagai perangkat fisik atau benda sehari-hari yang secara tradisional atau tanpa menggunakan internet. Tertanam dengan teknologi, perangkat ini dapat berkomunikasi dan berinteraksi melalui Internet, dan mereka dapat dimonitor dan dikendalikan dari jarak jauh.

Tidak diragukan lagi, kekuatan utama dari gagasan IOT adalah dampak tinggi yang akan terjadi pada beberapa aspek kehidupan sehari-hari dan perilaku pengguna potensial. Dari sudut pandang pengguna pribadi, efek yang paling jelas dari pengenalan IoT akan terlihat di lapangan kerja dan domestik. Dalam konteks ini, domotik, hidup berbantuan, e-health, peningkatan pembelajaran hanya merupakan beberapa contoh skenario aplikasi yang mungkin di mana paradigma baru akan memainkan peran utama dalam waktu dekat. Demikian pula, dari perspektif pengguna bisnis, konsekuensi yang paling nyata akan sama terlihat dalam bidang seperti, otomatisasi dan manufaktur industri, logistik, manajemen bisnis / proses, transportasi orang dan barang yang cerdas.

Struktur IoT didasarkan pada tiga lapisan; yaitu, lapisan persepsi (penginderaan), lapisan jaringan (transfer data), dan lapisan aplikasi (penyimpanan data dan manipulasi). Meskipun perbaikan besar, IoT masih terus berkembang, mencoba untuk mendapatkan bentuk akhirnya, seperti yang dapat dilihat di beberapa ulasan [4]. Seperti istilah "Internet" menyiratkan, kemampuan jaringan adalah salah satu fitur inti dari perangkat IOT. Internet seperti yang kita ketahui saat ini sebagian besar adalah internet pengguna akhir manusia, sedangkan IoT akan menjadi internet dari entitas non-manusia, oleh karena itu banyak komunikasi machineto-machine (M2M) akan berlangsung.

\subsection{Unsur Pembentuk IoT}

- Konektivitas - Dalam sebuah konsep IoT, memungkinkan adanya terbentuk sebuah jaringan baru maupun jaringan yang spesial untuk IoT. Sehingga jaringan IoT yang terbentuk tidak saling kebergantungan dengan jaringan utama atau jaringan umum lainnya.Keberadaan jaringan IoT tidaklah meski dalam keadaan besar dengan Jaringan yang berskala kecil sudah bisa bergantungan dengan IoT.

- Sensor - Sensor berfungsi sebagai penangkap sinyal. Dengan adanya sensor bisa menjelaskan instrumeninstrumen yang ada, sehingga mengubah fungsi IoT dari kegiatan pasif menjadi aktif dikarenakan banyak nya input dan output yang dihasilkan.

- Keterlibatan Aktif - Dengan adanya Engagement mampu membuat IoT yang lebuh aktif dan bersinergi. 


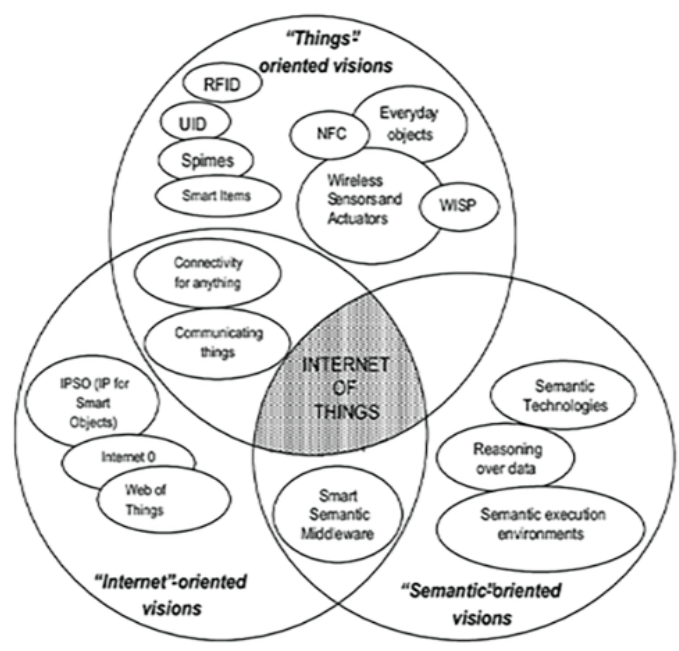

Gambar 1. Paradigma “Internet of Things ” Sebagai Hasil Dari Konvergensi Berbagai Visi.

Sehingga membuat IoT semakin banyak fungsi yang dihasilkan

- Perangkat Berukuran Kecil - Dengan keberadaan perangkat yang semakin kecil memungkinkan fleksibitas yang baik. Kemudian dengan piranti ini bisa diakses dengan cepat.Menggambarkan tentang cara mengumpulkan data untuk menyelesaikan penelitian.

\subsection{Konsep Teori}

Internet of Things biasanya disusun oleh tiga bagian, yaitu, sistem RFID, sistem Savant middleware dan sistem Internet “ Kapan saja, di mana saja, media apa pun "telah lama visi yang mendorong maju kemajuan dalam teknologi komunikasi. Dalam konteks ini, teknologi nirkabel telah memainkan peran kunci dan saat ini rasio antara radio dan manusia mendekati nilai 1 hingga 1 .

Secara umum, rantai pasokan pertanian hijau terdiri dari empat bidang: rantai produksi pasokan, Link produksi, pengolahan dan tautan ritel. Green Agricultura Model rantai suplai adalah struktur jaringan, yang ditentukan oleh logistik, arus informasi dan aliran modal melaluinya. Tujuan utama organisasi suplai rantai adalah untuk rantai arus informasi, logistik, aliran modal dan sebagainya, dan mengintegrasikan ke permintaan konsumen, akhirnya memaksimalkan kepuasan pelanggan dan rantai pasokan untuk meminimalkan keseluruhan biaya keseimbangan produksi dalam rantai pasokan. Akhirnya, itu membentuk mekanisme organisasi internal yang efektif untuk melindungi kepentingan tugas keseluruhan organisasi rantai pasokan $[5,6]$.

Oleh karena itu, kami ditemukan ide baru tentang pemantauan panen dan pertanian cerdas menggunakan IoT. Konsep ini menggunakan kehandalan dan pemantauan jarak jauh. Idenya mencoba untuk mendigitalkan kegiatan pertanian dan pertanian sehingga petani dapat memeriksa persyaratan tanaman dan secara akurat memprediksi pertumbuhan mereka. Konsep ini pasti akan mempercepat bisnis mereka untuk mencapai ketinggian baru dan juga lebih menguntungkan. Pelaksanaan kegiatan ini sebagian besar tergantung pada kesadaran di kalangan petani, yang, akan mudah dibuat karena banyak keuntungannya.

\section{METODELOGI PENELITIAN}

\subsection{Hardware}

Perangkat Keras yang digunakan untuk Proyek adalah Raspberry Pi3 dan perangkat keras yang diperlukan untuk proyek tercantum di bawah ini :

1. Analog Sensor Kelembaban Tanah DHT22

2. Digital Temperature and Humidity Sensor MQ-135

3. Modul Sensor Gas Kualitas Udara MQ-7 Gas 


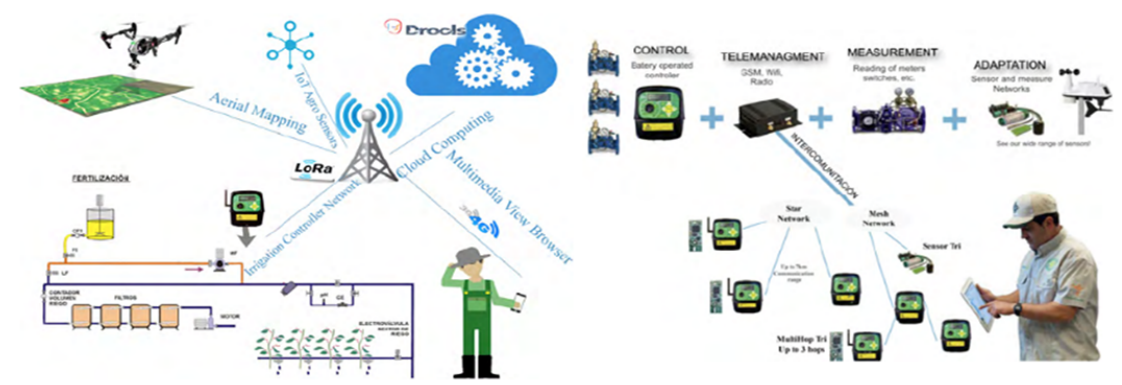

Gambar 2. Contoh Penerapan IoT di Smart Farm [7].

4. Sensor suara ultrasonik Layar

5. LCD $16 \times 2$ Alfanumerik (JHD162A)

6. Jumper Kabel

7. Modul Modem GSM un

8. Powersupply 5 Volt 1

\subsection{Software}

Adapun perangkat lunak yang digunakan berupa :

1. Raspbian OS

2. Python

3. PHP Server

\subsection{Perencanaan Penelitian}

Penelitian ini ditujukan untuk memonitoring terhadap sistem Smart Agro Tech Farm Sistem. Nantinya penelitian ini akan menghasilkan sebuah software yang dapat membaca Pengontrolan Air, Pupuk, dan sensor sensor dari setiap tanaman yang ada pada Smart Agro Tech Farm Sistem. Adapun ilustrasi dari perencanaan penelitian ini adalah sebagai berikut (Gambar 3).

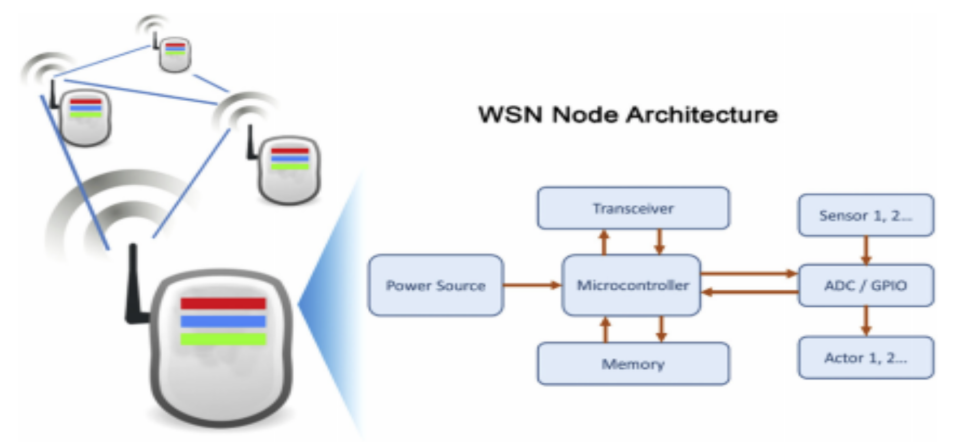

Gambar 3. Model Pengembangan Aplikasi Sistem.

Adapun Alur dari Perancangan sistem bisa dilihat pada gambar 4 berikut : 


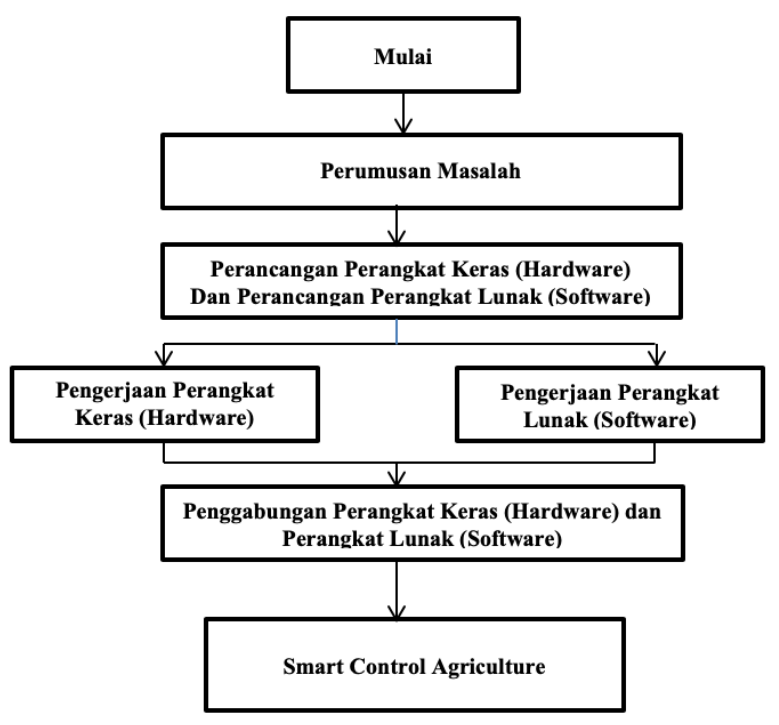

Gambar 4. Perancangan Sistem.

\section{HASIL DAN PEMBAHASAN}

\subsection{Model Rancangan Penelitian}

Perancangan sistem IoT ini dilakukan pada greenhouse meliputi perancangan perangkat lunak (software) dan perangkat keras (hardware). Sistem yang dirancang akan membentuk suatu sistem pengendali temperatur, kelembaban, dan intensitas cahaya. Pengendalian dilakukan dengan mengendalikan besarnya temperatur, kelembaban dan kuantitas cahaya dalam greenhouse. Sistem yang akan dibuat di sini adalah Monitoring Kontrol Greenhouse untuk Budidaya Tanaman Selada. Adapun greenhouse yang di buat seperti ditunjukkan pada gambar 5 .

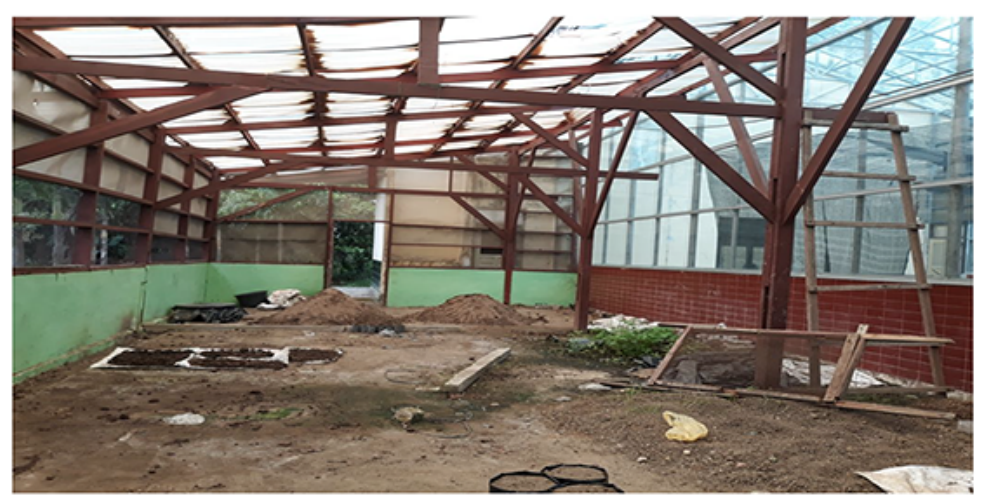

Gambar 5. Desain Greenhouse.

\subsection{Diagram Blok Sistem}

Diagram blok sistem greenhouse ditunjukkan pada gambar 6. Sistem terdiri atas beberapa bagian dengan fungsi masing - masing akan dijelaskan kemudian.

1. Sensor cahaya dan driver, sebagai sinyal untuk mendeteksi besarnya itensitas cahaya (lux) dalam greenhouse. 


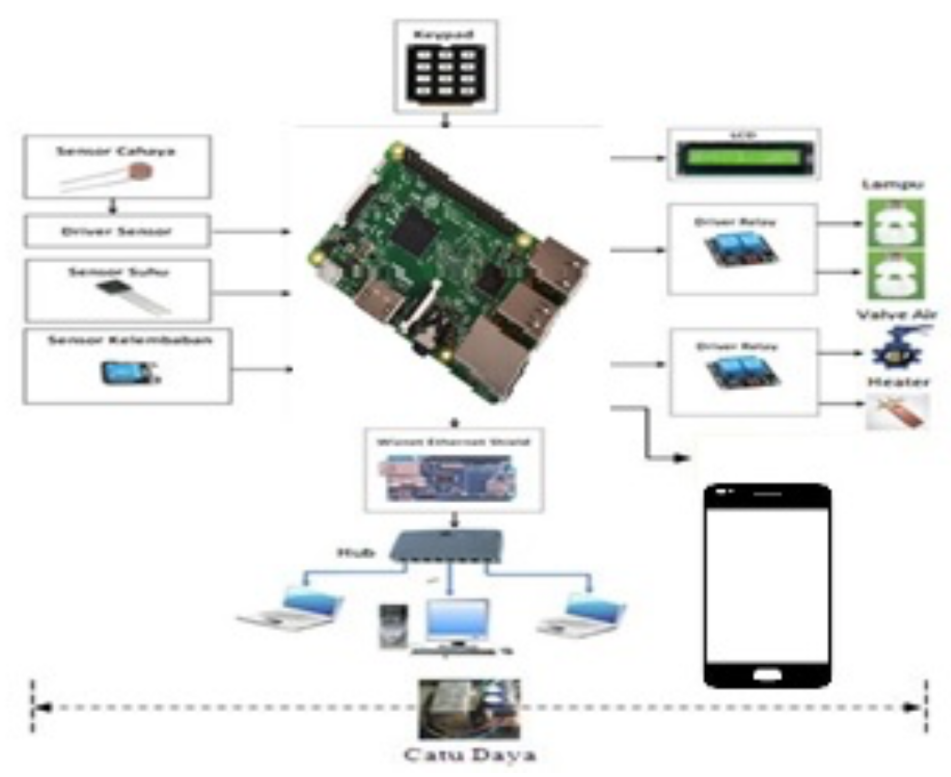

Gambar 6. Diagram Blok Sistem Greenhouse.

2. Sensor suhu, sebagai sinyal untuk mendeteksi temperatur dalam derajat celcius dalam greenhouse.

3. Sensor kelembaban, untuk mendeteksi kelembaban udara dalam greenhouse.

4. Keypad, digunakan sebagai set point pada batasan intensitas cahaya, suhu, dan kelembaban.

5. Mikrokontroler Arduino Mega sebagai pusat kendali dari sistem greenhouse, menerima sinyal yang diberikan, memproses, kemudian hasilnya digunakan untuk mengendalikan driver-driver relay.

6. LCD, sebagai display tampilan sinyal cahaya, suhu, dan kelembaban.

7. Driver relay sebagai penggerak on/off pada lampu, valve, dan heater.

8. Wiznet Ethernet Shield digunakan untuk menampilkan data dalam jaringan komputer (LAN) dengan kemampuan TCP/IP. Ethernet shield dihubungkan dengan komputer melalui hub menggunakan kabel konektor RJ45.

9. Laptop / desktop PC digunakan untuk monitoring sistem

\subsection{Pengujian Sistem}

Pengujian dilakukan untuk mengetahui kinerja sistem hasil perancangan, apakah berfungsi dengan baik dan sesuai dengan spesifikasi sistem yang direncanakan. Data hasil pengujian akan dianalisis untuk dijadikan acuan dalam mengambil kesimpulan. Pada pengujian sistem, hardware dan software terintegrasi dalam satu kesatuan sistem. Pengujian dilakukan dengan memadukan parameter hardware yang kemudian dijalankan melalui sistem programmable. Saat sistem dijalankan, kontroler akan menginisialisasi alamat serta fungsi dari masing-masing parameter pendukung, kemudian melakukan proses pengisian set point melalui keypad. Metode pengujian pada setiap variabel sistem kontrol dan pengujian sistem terintegrasi secara terpadu pada greenhouse.

\section{KESIMPULAN}

Pada penelitian ini telah berhasil dirancang sebuah sistem pengontrolan tanaman yang bisa langsung dikontrol via perangkat smartphone. Prototipe ini dibangun melalui sebuah rumah kasa/kaca. Perlu peningkatan lebih luas dengan penerapan di lahan yang lebih luas agar hasil yang didapat bisa lebih maksimal. Sehingga nantinya bisa membantu para petani dalam mengelola pertaniannya. Penelitian lanjutan perlu dilakukan untuk melihat seberapa besar pengaruh sensor dalam mendeteksi perkembangan tumbuh tanaman, tingkat kesuburan tanah, dan pendeteksian terhadap hama. 


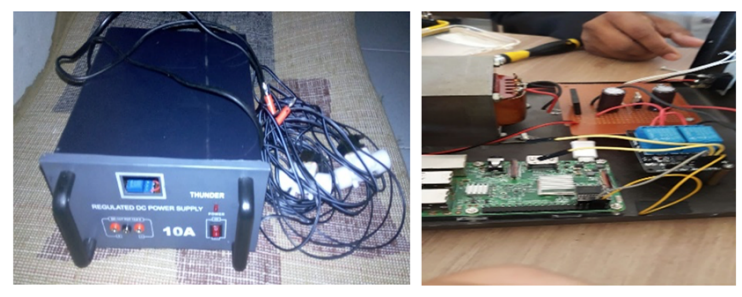

Gambar 7. Konsep Alat.

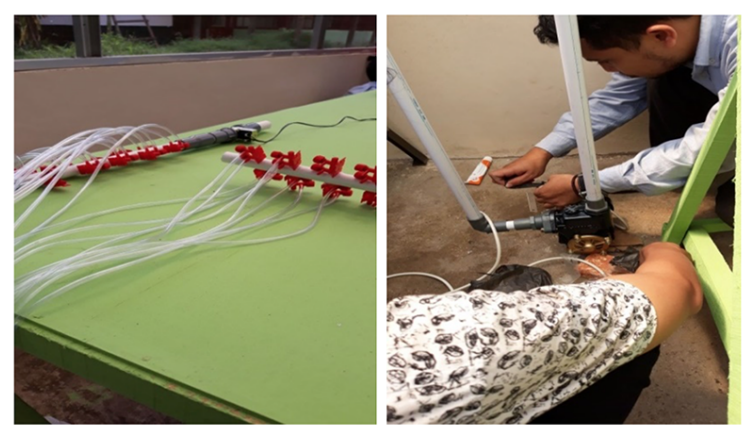

Gambar 8. Instalasi Air.

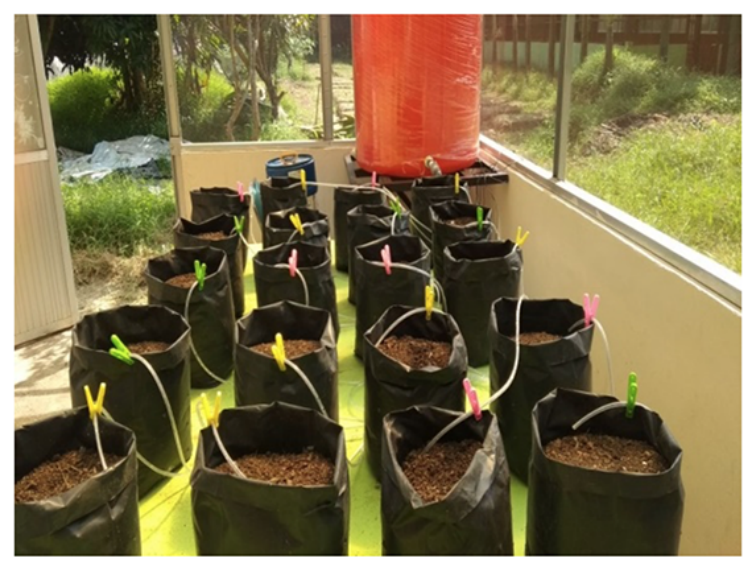

Gambar 9. Instalasi saat Pembibitan.

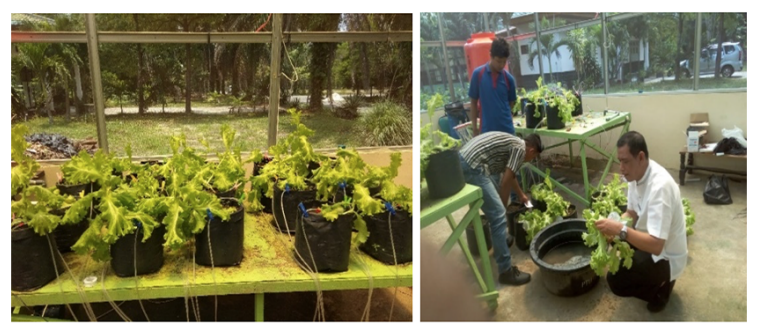

Gambar 10. Proses Pemanenan.

\section{UCAPAN TERIMA KASIH}

Penulis mengucapkan kepada Fakultas Ilmu Komputer Universitas Lancang Kuning yang telah memberikan pendanaan dalam penelitian ini. Penelitian ini dibiayai melalui Skema APBF-Fasilkom Unilak Tahun 2019. 


\section{DAFTAR PUSTAKA}

[1] I. Mohanraj, K. Ashokumar, and J. Naren, "Field monitoring and automation using iot in agriculture domain," Procedia Computer Science, vol. 93, pp. 931-939, 2016.

[2] D. Giusto, A. Iera, G. Morabito, and L. Atzori, The internet of things: 20th Tyrrhenian workshop on digital communications. Springer Science \& Business Media, 2010.

[3] P. Bellavista, G. Cardone, A. Corradi, and L. Foschini, "Convergence of manet and wsn in iot urban scenarios," IEEE Sensors Journal, vol. 13, no. 10, pp. 3558-3567, 2013.

[4] L. Atzori, A. Iera, and G. Morabito, "The internet of things: A survey," Computer networks, vol. 54, no. 15, pp. 2787-2805, 2010.

[5] L. Li, "Application of the internet of thing in green agricultural products supply chain management," in 2011 Fourth International Conference on Intelligent Computation Technology and Automation, vol. 1. IEEE, 2011, pp. 1022-1025.

[6] F. Brandt, "Efficient cryptographic protocol design based on distributed el gamal encryption," in International Conference on Information Security and Cryptology. Springer, 2005, pp. 32-47.

[7] C. Cambra, S. Sendra, J. Lloret, and L. Garcia, "An iot service-oriented system for agriculture monitoring," in 2017 IEEE International Conference on Communications (ICC). IEEE, 2017, pp. 1-6.

\section{BIOGRAFI PENULIS}

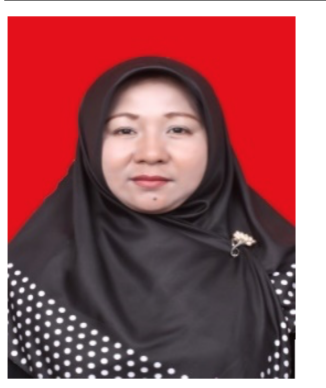

Nurliana Nasution, ST., M.Kom Lahir di Pekanbaru tanggal 3 Maret 1972. Pendidikan Sekolah Dasar hingga SMA di selesaikan di Kota Pekanbaru. Tahun 1998 Lulus S1 dari Fakultas Teknologi Industri Universitas Pembangunan Nasional Veteran Surabaya, Jawa Timur. Pendidikan S2 diselesaikan Tahun 2005 dari Program Pasca Sarjana Magister Ilmu Komputer UPI YPTK Padang, Sumatera Barat. Tahun 2000 sampai 2006 Dosen Fakultas Pertanian Universitas Lancang Kuning. Tahun 2006 sampai sekarang menjadi Dosen Tetap pada Fakultas Ilmu Komputer Universitas Lancang Kuning Pekanbaru.

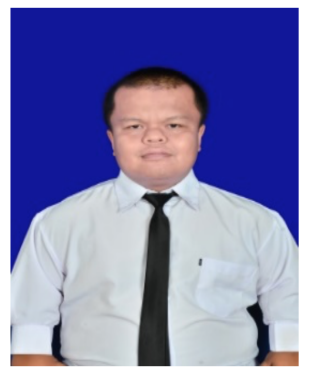

Mhd Arief Hasan, M.Kom Lahir di Bukittinggi tanggal 21 Juni 2987. Pendidikan Sekolah Dasar hingga SMA diselesaikan di Kota Bukittinggi. Tahun 2009 Lulus S1 dari Fakultas Ilmu Komputer UPI YPTK Padang Sumatera Barat. Pendidikan S2 diselesaikan Tahun 2012 dari Perguruan Tinggi yang sama. Aktif sebagai Dosen di Universitas Lancang Kuning Pekanbaru. Penulis sangat konsen dengan dunia Pemrograman terutama Pemrograman Web dan Mobile. 